\title{
Identification of a gene expression profile associated with the regulation of angiogenesis in endometrial cancer
}

\author{
MARCIN OPŁAWSKI ${ }^{1}$, MATEUSZ MICHALSKI ${ }^{2}$, ANDRZEJ WITEK ${ }^{3}$, BOGDAN MICHALSKI $^{4}$, \\ NIKOLA ZMARZŁY ${ }^{5}$, AGNIESZKA JĘDA-GOLONKA ${ }^{2}$, MARIA STYBLIŃSKA ${ }^{5}$, JOANNA GOLA ${ }^{5}$, \\ MAŁGORZATA KASPRZYK-ŻYSZCZYŃSKA ${ }^{1}$, URSZULA MAZUREK $^{5}$ and ANDRZEJ PLEWKA ${ }^{1}$
}

\author{
${ }^{1}$ Department of Proteomics, School of Pharmacy, Division of Medical Analytics, Medical University of Silesia, \\ Sosnowiec 41-200; ${ }^{2}$ Department of Gynecological Oncology, Gynecology and Obstetrics, Regional Railway Hospital, \\ Katowice 40-760; ${ }^{3}$ Department of Gynecology, Obstetrics and Oncologic Gynecology, Medical University \\ of Silesia; ${ }^{4}$ Department of Oncological Gynaecology, School of Health Sciences, Medical University \\ of Silesia, Katowice 40-752; ${ }^{5}$ Department of Molecular Biology, School of Pharmacy, Division \\ of Medical Analytics, Medical University of Silesia, Sosnowiec 41-200, Poland
}

Received October 26, 2016; Accepted February 20, 2017

DOI: $10.3892 / \mathrm{mmr} .2017 .6868$

\begin{abstract}
The publication of the human genome sequence provided direction in the search for novel diagnostic and therapeutic methods for the treatment of human diseases. The aim of the present study was to investigate the hypothesis that the expression profile of genes involved in the regulation of angiogenesis may be a marker in endometrial cancer that facilitates the diagnosis and prognosis of patients, as well as the identification of novel therapeutic targets. The current study included 36 patients with grade (G) 1 to 3 endometrial cancer, and a control group of patients consisting of females that qualified for the removal of the uterus. Out of these, 28 samples (control, 3; $\mathrm{G} 1,7 ; \mathrm{G} 2,12$; and $\mathrm{G} 3,6$ ) were selected for microarray analysis. Molecular analysis of the endometrial samples involved the extraction of total RNA, purification of the obtained extracts and subsequent analysis of the gene expression profiles using an oligonucleotide microarray technique (GeneChip ${ }^{\circledR}$ Human Genome U133A plates). The results indicated that the mRNA expression profile of genes involved in the regulation of angiogenesis varies depending on the degree of histological differentiation of endometrial adenocarcinoma. Similar results were obtained from descriptive statistics characterizing the expression profile of $691 \mathrm{mRNAs}$ associated with the regulation of angiogenesis in the groups of patients with endometrial adenocarcinoma. In addition, the results of the present study
\end{abstract}

Correspondence to: Professor Andrzej Plewka, Department of Proteomics, School of Pharmacy, Division of Medical Analytics, Medical University of Silesia, 8 Jedności Street, 41-200 Sosnowiec, Poland

E-mail: aplewka@sum.edu.pl

Key words: endometrial cancer, angiogenesis, vascular endothelial growth factor, vascular endothelial growth factor receptor, gene expression, apoptosis, prognosis, microarray indicated that neuropilin2 (NRP2) may serve an important role in the activity of endothelial cells, and may affect vascular endothelial growth factor, and potentially plexins and integrins via regulation of their functions. An understanding of how these proteins interact remains to be determined; however, elucidating these interactions may provide an explanation for the mechanisms underlying angiogenesis. In conclusion, the results of the present study suggest that NRP2 may be a valuable target for investigation in future pharmacological studies involving angiogenesis in endometrial cancer.

\section{Introduction}

The publication of the human genome sequence increased the ability to identify novel diagnostic and therapeutic methods for the treatment of human diseases. The combination of morphological methods, the well-established biology of premalignant and invasive alterations, together with molecular biology techniques, which enables the expression of several hundred or even several thousand genes to be evaluated simultaneously, increases the precision of diagnosis and therapy and leads to the development of effective targeted molecular therapies for patients. The ability to use molecular criteria for the selection of an appropriate therapy for a particular patient has led to the rapid development of personalized medicine, particularly in oncology (1-3). Individualization of patient treatment involves adapting therapies to the individual characteristics of the particular patient and their disease. Personalized medicine increases the likelihood that an appropriate, effective and safe therapy is selected. For this reason, molecular biology techniques are increasingly becoming a widespread diagnostic tool in clinical practice $(4,5)$. Molecular diagnostics facilitates the detection of neoplastic lesions in high-risk individuals at an early stage of disease, as alterations at the molecular level precede alterations at the phenotypic level. In addition, it enables the detection of drug resistance, which allows the precision of the treatment strategy to be improved. 
Various mechanisms are associated with an altered expression profile of genes involved in the regulation of angiogenesis $(6,7)$. Understanding these differences may be important for diagnosis and therapy. One current method of effective anticancer therapy is an anti-angiogenic therapy that targets products of genes involved in the regulation of angiogenesis. This treatment demonstrates a positive effect in numerous cancer types; however, extended duration of treatment often results in drug resistance $(8,9)$. Maintaining anti-angiogenic therapy sometimes requires change of the drug as well as the molecular target due to drug resistance (10-12). Consequently, the search for novel targets for targeted therapy is ongoing $(13,14)$.

Cancer of the uterus lining, also termed the endometrium, is one of the most commonly diagnosed gynecological cancers worldwide, and primarily affects postmenopausal women $(15,16)$. According to the World Health Organization classification system, there are three histological grades $(\mathrm{G})$ of endometrial cancer, including G1 (well differentiated), G2 (moderately differentiated) and G3 (poorly differentiated) (17). According to clinical, metabolic and endocrine characteristics, there are two types of endometrial cancer. Type I are estrogen-associated, low-grade (G1 and G2) and are often associated with obesity. They are diagnosed early, and therefore demonstrate a favorable prognosis. Type II are hormone-independent, high-grade (G3) and commonly occur in non-obese women. This type of endometrial cancer metastasizes early, and patients demonstrate a poorer prognosis when compared with type I endometrial cancers $(18,19)$. The authors of the present study hypothesized that the expression profile of genes involved in the regulation of angiogenesis may present diagnostic, prognostic and therapeutic targets in endometrial cancer. The aim of the current study was therefore to identify and select genes involved in the regulation of angiogenesis, which have altered transcriptional activity depending on the degree of histopathological differentiation of endometrial adenocarcinoma, that may present diagnostic, prognostic and therapeutic targets.

\section{Materials and methods}

Patients. The present study enrolled 36 patients, 30 with endometrial cancer with degrees of histopathological differentiation between G1 and G3 (the case study group), and a control group consisting of 6 patients without endometrial cancer that qualified for the removal of the uterus (hysterectomy) due pathologies of the uterus and adnexa. Patients in the control group that agreed to participate in the present study qualified for surgical removal of the uterus (abdominal hysterectomy) with the following medical indications: Uterine fibroids, benign tumors of the appendages, or reproductive organ prolapse. The patients were admitted into Regional Railway Hospital in Katowice from January to May 2015. The average age of patients in the study group was 65 and in the control group, 48. All patients provided written informed consent for the use of their samples in the present study. The criteria for exclusion from the case study group included patients that, according to medical history or postoperative pathological examination, were diagnosed with a form of cancer other than endometrial endometrioid adenocarcinoma. Additional exclusion criteria were the detection of endometrial hyperplasia with or without atypia during postoperative pathological examination, the use of hormone replacement therapy in the 5 years prior to the operation and extreme obesity (body mass index, $>40$ ). The histopathological assessments of tumor samples were performed in the Department of Pathomorphology, Medical University of Silesia (Katowice, Poland). A total of 28 samples (control, 3; G1, 7; G2, 12; and G3, 6) were selected for microarray analysis.

Ethical approval. The present study was approved by the Bioethical Committee of the Medical University of Silesia (Sosnowiec, Poland; no. KNW/0022/KB1/67/13). The study adhered to the tenets of the Declaration of Helsinki.

Molecular analysis. Molecular analysis of the endometrial samples from patients that had undergone a hysterectomy (study case group and control group) involved the extraction of total RNA using TRIzol ${ }^{\circledR}$ reagent (Invitrogen; Thermo Fisher Scientific, Inc., Waltham, MA, USA) according to the manufacturer's instructions. Extracted total RNA was then purified using an RNeasy Mini kit (Qiagen GmbH, Hilden, Germany) using columns and an RNase-Free DNase Set (Qiagen GmbH) according to the manufacturer's instructions. Analysis of gene expression profiles was determined using an oligonucleotide microarray technique with GeneChip ${ }^{\circledR}$ Human Genome U133A plates (Affymetrix, Inc., Santa Clara, CA, USA). The first step of the analysis was cDNA synthesis (8 $\mu \mathrm{g}$ RNA was used as a template) with the use of SuperScript Choice System (Invitrogen; Thermo Fisher Scientific, Inc.). Then, the synthesis of biotinylated cRNA was performed using BioArray HighYield RNA Transcript Labeling kit (Enzo Life Sciences, Farmingdale, NY, USA). Subsequently, the Sample Cleanup Module kit (Qiagen $\mathrm{GmbH}$, Germany) was used to perform fragmentation of the biotin-labeled cRNA. After the cRNA hybridized to the HG-U133A microarray, it was stained with streptavidin-phycoerythrin and scanned using GeneArray Scanner G2500A (Agilent Technologies, Inc., Santa Clara, CA, USA). The data was processed for signal values using Microarray Suite version 5.0 software (Affymetrix, Inc.). All of the procedures were performed as recommended by Affymetrix Gene Expression Analysis Technical Manual (20). Comparative analysis of the transcriptome was performed for 691 mRNA sequences of genes encoding proteins involved in the regulation of angiogenesis, which were selected based on the results of the literature, the NCBI database (Gene, http://ncbi.nlm.nih.gov/gene) and an Affymetrix NetAffx ${ }^{\mathrm{TM}}$ Analysis Center database (http://www.affymetrix.com/analysis/index.affx).

Statistical analysis. GeneSpring GX version 12.6.1 software (Agilent Technologies, Inc.) and PL-Grid Infrastructure (http://www.plgrid.pl/) were used for statistical analysis of the data after microarrays scanning. Microarray analysis was performed using the following specialized programs adapted to the analysis of the matrix experiment results: Microarray Suite 5.0 software (Affymetrix, Inc.), GeneSpring GX (version, 12.6.1; Agilent Technologies, Inc.) and PANTHER version 11.1 (Protein Analysis Through Evolutionary 

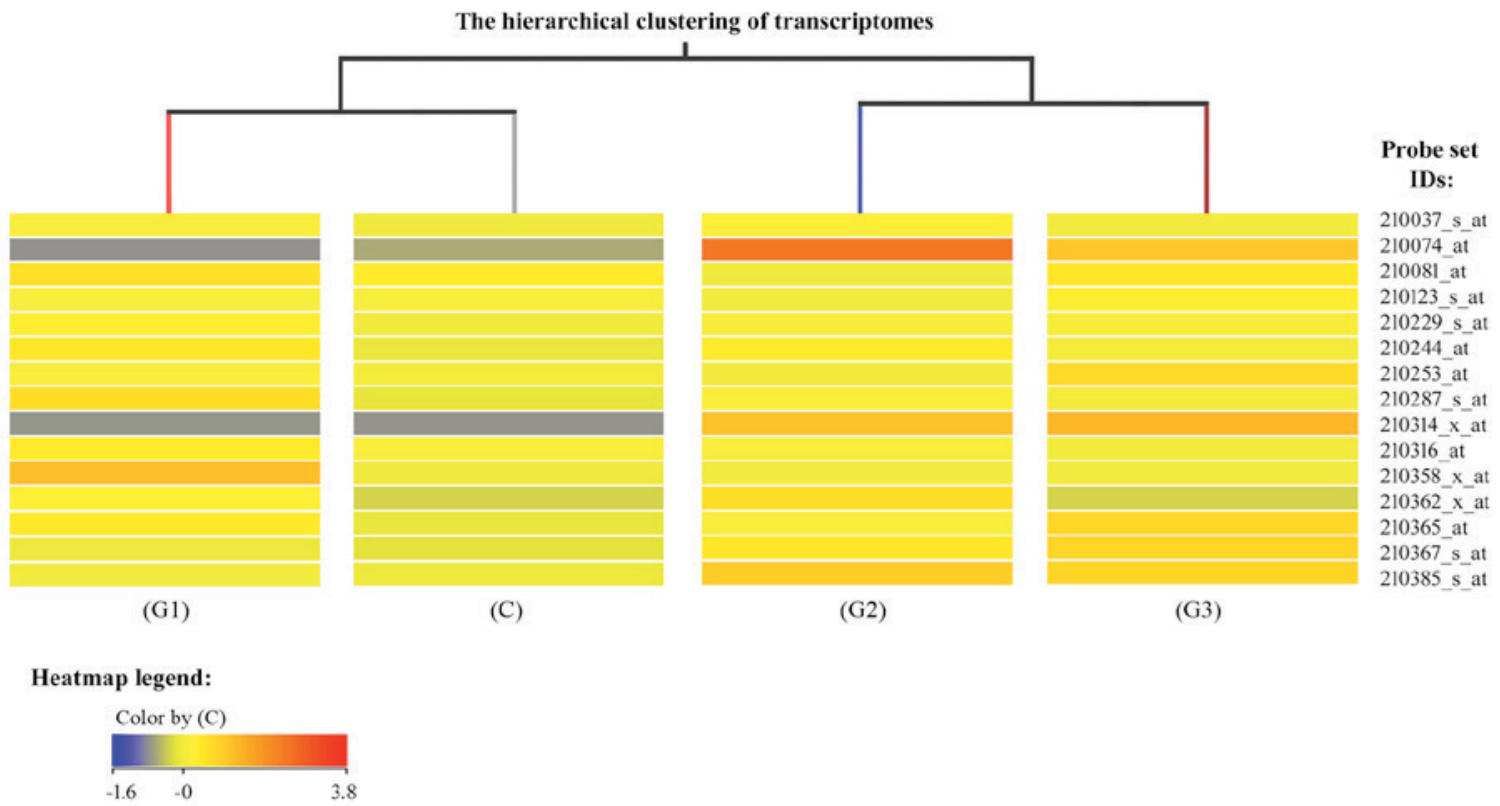

Figure 1. Fragment of a dendrogram representing the hierarchical clustering of transcriptomes among C, G1, G2 and G3 groups, which demonstrates the similarity of mRNA expression profiles of genes involved in the regulation of angiogenesis. The probe set IDs represent the mRNA sequences identified by an over-representation test using PANTHER software. The blue color indicates the lowest fluorescence signal, while red indicates the highest fluorescence signal C, control; G, grade of endometrial adenocarcinoma; ID, identification number.

Relationships, http://pantherdb.org) (21), Gene List Analysis tool. Initially, the degree of RNA degradation was assessed using $3^{\prime} / 5^{\prime}$ ratio (signal intensity ratio of the $3^{\prime}$ probe set over the $5^{\prime}$ probe set) of the housekeeping genes $G A P D H$ and $\beta$-actin. This parameter was termed RNA degradation index and is commonly used in Affymetrix U133 plates for RNA quality assessment. This index reflects the level of RNA integrity and accuracy of sample processing. A low index $\left(3^{\prime} / 5^{\prime}\right.$ ratio $\left.<3\right)$ corresponds to high quality material, whereas a high index $\left(3^{\prime} / 5^{\prime}\right.$ ratio $\left.>3\right)$ could indicate low quality material and/or problems during sample processing. The control of microarray hybridization with mRNA was based on the 8 exogenous controls, 8 probes complementary to the exogenous RNA added in varying concentrations to the hybridization cocktail by the manufacturer of the microarray (Affymetrix, Inc.). The following probes were used in the present study: AFFX-BioB_at, AFFX-BioC_at, AFFX-BioDn_at, AFFX-CreX_at, AFFX-r2-Ec-BioB_at, AFFX-r2-Ec-BioC_at,AFFX-r2-Ec-BioD_at,AFFX-r2-P1-cre_at. Following the acceptance of the microarray for comparative analysis, the obtained results were normalized using the Robust Multi-array Average (RMA) Express program version 1.1.0 (http://rmaexpress.bmbolstad.com/) (22), and genes that were differentially expressed in the transcriptome depending on the severity of the disease (histopathological grade) were selected for molecular analysis using GeneSpring GX software (version12.6.1). One-way analysis of variance (ANOVA) with the Benjamini-Hochberg correction was performed to identify mRNAs that exhibited significantly altered expression in endometrial adenocarcinoma samples compared with the controls. The Tukey's test was used for multiple comparisons. $\mathrm{P}<0.05$ was considered to indicate a statistically significant difference.

\section{Results}

The expression profiles of mRNA in endometrial samples with varying degrees of histological differentiation of endometrial adenocarcinoma were determined by microarray expression analysis using GeneChip ${ }^{\circledR}$ Human Genome U133A plates. Differentially expressed genes among the groups were first normalized using the RMA Express program. Hierarchical clustering of the results was then performed, which allowed a preliminary assessment of the similarity between mRNA expression profiles in the different groups (Fig. 1). Fig. 1 is a fragment of a dendogram showing expression of 15 mRNAs, it demonstrates that the mRNA expression profile of genes involved in the regulation of angiogenesis varies depending on the degree of histological differentiation of endometrial adenocarcinoma. The smallest differences relative to the control group were observed in the G1 group of endometrial adenocarcinomas, while the transcriptomes of G2 and G3 groups constituted a distinct subgroup (Fig. 1). Similar conclusions were drawn based on descriptive statistics characterizing the expression profile of 691 mRNAs associated with the regulation of angiogenesis in the control and endometrial adenocarcinoma groups (Fig. 2).

To determine which of the observed differences in mRNA expression were statistically significant, one-way ANOVA was performed. The results indicated that, out of the $691 \mathrm{mRNAs}$, 585 mRNAs were significantly differentially expressed in endometrial adenocarcinoma samples when compared with controls. Table I presents the level of significance for mRNAs that demonstrated significantly altered expression in endometrial adenocarcinoma samples when compared with controls. Multiple comparisons testing was subsequently performed using the Tukey post hoc test to obtain more detailed 
Table I. Number of mRNA sequences associated with angiogenesis that were significantly, differentially expressed in patients with endometrial adenocarcinoma when compared with controls.

\section{P-value}

Number of mRNAs

$\begin{array}{lr}>0.020 \text { to }<0.050 & 203 \\ >0.010 \text { to }<0.020 & 140 \\ >0.005 \text { to }<0.010 & 115 \\ >0.001 \text { to }<0.005 & 82 \\ <0.001 & 45\end{array}$

The expression of a total of 691 mRNAs associated with the regulation of angiogenesis was compared between controls and patients with endometrial adenocarcinoma, 585 exhibited significantly altered expression levels.

Table II. Number of mRNA sequences that were differentially expressed among the transcriptome groups.

\begin{tabular}{lrrrr}
\hline Transcriptome group & C & G1 & G2 & G3 \\
\hline C & 203 & $27^{\mathrm{a}}$ & $113^{\mathrm{a}}$ & $81^{\mathrm{a}}$ \\
G1 & 176 & 203 & $86^{\mathrm{b}}$ & $90^{\mathrm{b}}$ \\
G2 & 90 & 117 & 203 & $32^{\mathrm{c}}$ \\
G3 & 122 & 113 & 171 & 203
\end{tabular}

$\mathrm{C}$, control; G, grade of endometrial adenocarcinoma. ${ }^{\mathrm{a}} \mathrm{P}<0.05$ vs. $\mathrm{C}$ group, ${ }^{\mathrm{b}} \mathrm{P}<0.05$ vs. $\mathrm{G} 1$ group, ${ }^{\mathrm{c}} \mathrm{P}<0.05$ vs. $\mathrm{G} 2$ group.

information regarding the differences between mRNA levels among different histological grades of endometrial adenocarcinoma and controls (Table II). The results indicated that the number of mRNAs with significantly altered expression when compared with the controls for each histological grade were as follows: G1 vs. control, 27; G2 vs. control, 113; and G3 vs. control, $81(\mathrm{P}<0.05$; Table II). Therefore, the number of mRNAs that demonstrated significantly altered expression in endometrial adenocarcinoma samples compared with the controls varied depending on whether they were G1, G2 or G3 samples.

A Venn diagram was constructed to demonstrate the number of overlapping mRNAs that exhibited significantly altered expression levels among endometrial adenocarcinoma samples of any histological grade and the controls (Fig. 3). The results indicate that six mRNAs differentiated endometrial adenocarcinoma samples from the control regardless of histological grade (Fig. 3). The number of mRNAs that were significantly differentiated between specific histological grades and controls (significantly altered expression in only one histological grade vs. controls) were as follows: G1 vs. control, 15; G2 vs. control, 43; and G3 vs. control, 15 mRNA (Fig. 3).

This next step of the analysis was completed by performing an over-representation test using PANTHER software (Gene List Analysis). This allowed for the identification of differentially expressed mRNAs that are essential for tumor

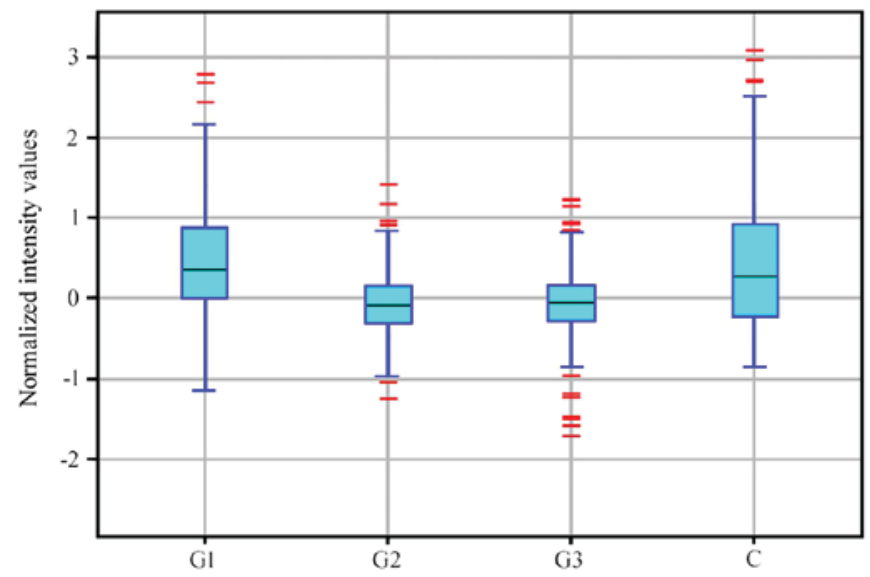

Figure 2. Box-and-whisker plot of the normalized fluorescence intensity values of 227 mRNA sequences of transcriptomes in the C, G1, G2 and G3 groups. Black lines indicate median values, the height of the rectangle indicates the interquartile range, and red lines indicate signals deviating from the interquartile range by $\geq 150 \%$. C, control; $\mathrm{G}$, grade of endometrial adenocarcinoma.

angiogenesis (Table III). The results demonstrated that in G1 endometrial adenocarcinoma, three genes, including endoglin (ENG), EGF like repeats and discoidin domains 3 (EDIL3) and neuropilin 2 (NRP2) demonstrated a significant increase in expression when compared with the control group (Table III). In addition, a significant increase in the mRNA expression levels of semaphorin (SEMA) 3B in G2 endometrial adenocarcinomas, and SEMA3F expression in G3 endometrial adenocarcinoma was observed when compared with the control group (Table III). The remaining mRNAs identified by the over-representation test that were determined to be important for tumor angiogenesis, occurred in G2 and G3 endometrial adenocarcinoma at an expression level that was significantly lower when compared with the control. A characteristic feature was that the mRNA level was gradually reduced with the increase of histopathological differentiation of endometrial adenocarcinoma (Table III). The overlapping mRNAs between the G2 vs. control and G3 vs. control groups included the transforming grow th factor $\beta$ receptor 3 (TGFBR3) isoform of ENG, formed due to post-transcriptional modification of the TEK receptor tyrosine kinase, vascular endothelial growth factor C (VEGFC), SEMA5A and homebox A5. The over-representation test did not identify mRNA sequences that differentiated all histological grades of endometrial adenocarcinoma (G1 vs. control, G2 vs. control and G3 vs. control) from controls. Similarly, no mRNAs that were common among G1 and $\mathrm{G} 2$ vs. control or G1 and G3 vs. control groups were identified as essential for tumor angiogenesis (Table III).

\section{Discussion}

Microarray technology facilitates detection of the expression levels of several thousand genes with one experiment, and is therefore a useful tool for determining the influence of changes in gene expression levels in the development of human disease, such as cancer (23). The results of the present study suggest that the expression of genes involved in the regulation of angiogenesis may present a useful diagnostic marker 
Table III. Genes essential for the regulation of angiogenesis in different histological grades of endometrial adenocarcinoma.

\begin{tabular}{|c|c|c|c|c|c|}
\hline \multirow[b]{2}{*}{ Groups compared } & \multirow{2}{*}{$\begin{array}{l}\text { Total number of } \\
\text { differentially expressed mRNAs }{ }^{a}\end{array}$} & \multicolumn{4}{|c|}{ mRNAs important for tumor angiogenesis } \\
\hline & & ID & Symbol & P-value & $\mathrm{FC}(\log 2)$ \\
\hline \multirow[t]{3}{*}{ G1 vs. C } & 15 & 201808_s_at & ENG & 0.0013 & (+) 1.66033 \\
\hline & & 207379_at & EDIL3 & 0.0018 & (+) 1.79402 \\
\hline & & 214632_at & NRP2 & 0.0130 & (+) 1.85248 \\
\hline G2 vs. C & 43 & 203070_at & SEMA3B & 0.0019 & (+) 1.50104 \\
\hline G3 vs. C & 15 & 35666_at & SEMA3F & $<0.001$ & (+) 1.55995 \\
\hline G1 vs. $C$; $\mathrm{G} 2$ vs. $\mathrm{C}$ & 5 & - & - & - & - \\
\hline G1 vs. $\mathrm{C} ; \mathrm{G} 3$ vs. $\mathrm{C}$ & 1 & - & - & - & - \\
\hline \multirow[t]{6}{*}{ G2 vs. C; G3 vs. C } & 59 & 206702_at & TEK & $<0.001$ & (-) 2.15583 \\
\hline & & 209946_at & VEGF C & $<0.001$ & (-) 2.33019 \\
\hline & & 201809_s_at & ENG & $<0.001$ & (-) 2.74506 \\
\hline & & 205405_at & SEMA5A & $<0.001$ & (-) 3.05802 \\
\hline & & 213169_at & SEMA5A & 0.0052 & (-) 3.51414 \\
\hline & & 213844_at & HOXA5 & 0.0067 & (-) 3.53497 \\
\hline G1 vs. $\mathrm{C}$; $\mathrm{G} 2$ vs. $\mathrm{C}$; G3 vs. $\mathrm{C}$ & 6 & - & - & - & - \\
\hline
\end{tabular}

Genes were identified by one-way analysis of variance with a Tukey's post hoc test, followed by Venn diagram construction using the GeneSpring GX program, and over-representation analysis using the Gene List Analysis tool in PANTHER. A total of 27 mRNA sequences were identified in the G1 vs. C group, 113 mRNA sequences in the G2 vs. C group and 81 mRNA sequences in the G3 vs. C group.'(+)' indicates overexpression of a gene/increase in mRNA levels, while '(-)' indicates gene silencing/decrease in mRNA levels. ID represents the mRNA sequences identified by an over-representation test using PANTHER. ID, identification number; FC, fold-change; C, control; G, grade of endometrial adenocarcinoma; ENG, endoglin; EDIL3, EGF like repeats and discoidin domains 3; NRP2, neuropilin 2; SEMA, semaphorin; TEK, TEK receptor tyrosine kinase; VEGF C, vascular endothelial growth factor C; HOXA5, homeobox A5.

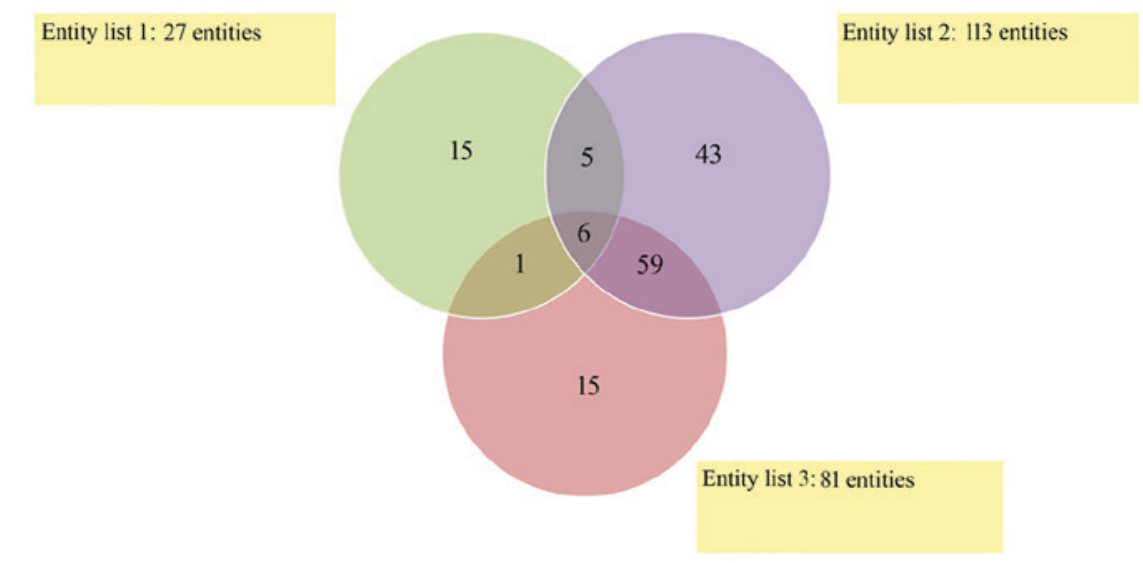

Figure 3. Venn diagram grouping of differentially expressed mRNA sequences among G1, G2 and G3 groups compared with the C group. Entity list 1, G1 vs. C; entity list 2, G2 vs. C; Entity list 3, G3 vs. C. C, control; G, grade of endometrial carcinoma.

that facilitates differentiation between low and high grades of endometrial adenocarcinoma.

Neoangiogenesis is associated with the expression of certain markers of angiogenesis, including VEGF, ENG (transmembrane glycoprotein receptor for TGF- $\beta$ ) and NRP (a co-receptor for VEGF) (24-27). Conventionally, the prediction of malignancy and treatment of cancer patients is based primarily on the determination of the clinical stage. Understanding the cellular processes responsible for the metastasis of cancer, as well as the molecular markers of invasiveness, may be useful to improve the diagnosis and prognosis of the disease. In addition, this understanding may facilitate the development of drugs targeting the factors responsible for the invasiveness of cancer and the enable the development of novel therapeutic regimens. ENG serves an important role in tumor progression via the regulation of angiogenesis, cell migration and metastasis. It is present on the surface of endothelial cells of tumor blood vessels and particular types of tumor cells. ENG is an auxiliary co-receptor of TGF- $\beta$ that is responsible for cell proliferation, differentiation, migration and adhesion (28-31). It is known that TGF- $\beta 1$ functions as an inhibitory factor during tumor development. In addition, 
it induces inflammation and releases angiogenic factors from inflammatory cells in vivo (32). It was previously demonstrated that inhibition of ENG stimulates cell growth induced by TGF- $\beta 1$ and inhibits cell migration (33). By contrast, ENG is an identified component of the endothelial nitric oxide synthase signaling pathway, which modulates the activity of cyclooxygenase-2 $(34,35)$. ENG appears to modulate the transition from endothelial progenitor cells to active endothelial cells (36).

Angiogenesis is essential for numerous physiological and pathological processes, such as tumor progression, as vascularization is required for tumor growth and metastasis (37). When there is an insufficient blood supply, cancer cells undergo apoptosis/necrosis. However, due to the observed distribution of ENG in all tissues and the other proven functional involvement with TGF- $\beta(38,39)$, it was demonstrated to be involved in angiogenesis $(25,40)$. The participation of ENG in angiogenesis corresponds with the observed death of $\mathrm{ENG}^{-/-}$knockout mice by vascular malformations (40). An association between the levels of ENG and cell proliferation markers, such as Ki-67 were observed (25). Using immunohistochemistry, increased expression of ENG has been observed in endothelial cells undergoing active angiogenesis, including those in the tumor, when compared with normal endothelium $(41,42)$. The function of ENG may be contradicting as it is required for tumor neoangiogenesis; however, the overexpression of this gene may act as a suppressor of invasion and metastasis (43). ENG as a part of the TGF- $\beta$ receptor complex modulates TGF- $\beta$ receptor signaling. The complex relays contradicting signals from TGF- $\beta$ that has a paradoxical role in cancer development. It may inhibit cell growth and induce apoptosis or differentiation during the premalignant phase of carcinogenesis. Conversely, TGF- $\beta$ may modulate processes such as cell invasion, angiogenesis, immune regulation after the cancer cells lose inhibitory growth responses, which allows them to become malignant (44). Previous studies observed that downregulation of endoglin was associated with malignant progression in prostate carcinoma cell lines and enhanced migration and invasion of nontumorigenic prostate cell lines, while overexpression had the opposite effect $(45,46)$. The present study, revealed that ENG was overexpressed in the G1 vs. control group [FC=(+)1.66033]. Therefore, it may be assumed that the increase in ENG mRNA levels may lead to inhibition of cell growth, and will thus function to inhibit tumor growth. From the G2 vs. control and G3 vs. control transcriptome groups, PANTHER highlighted ENG as a differentially expressed gene. However, in this case, decreases in mRNA expression levels [FC $=(-) 2.7451]$ were observed. As a consequence, TGF- $\beta$ may induce tumor cell growth and the likelihood of tumor progression may increase.

The expression of NRPs is observed in healthy, mature and developing vasculature systems, on endothelial cells, vascular smooth muscle cells $(47,48)$ and in the vascular endothelium surrounding tumors $(47,49-51)$. This is an important observation concerning the role of NRPs in the promotion of angiogenesis in cancer. Previous studies have indicated that NRPs are proangiogenic mediators that bind to VEGF. However, they may possess antiangiogenic roles by interacting with class 3 SEMAs (52). SEMA3 family proteins bind to the a1/a2 domains, whereas VEGF family proteins bind to the b1/b2 domains. Previous studies revealed that anti-Nrp1 antibody (anti-Nrp1A), that blocks the SEMA3 binding domain, does not block VEGF binding, whereas the antibody blocking the VEGF binding domain (anty-Nrp1B) does not block binding to SEMA3 $(9,53)$. There is sufficient evidence to indicate that SEMAs are involved in the regulation of apoptosis, cell migration, tumor growth and angiogenesis (54-57). SEMA3 particularly affects endothelial cells $(54,58,59)$. NRP2 preferentially binds to SEMA3B, 3C, 3D and 3F $(54,55,60)$. By inhibiting the interaction between VEGF-NRP, the SEMA3F isoform inhibits VEGF-dependent cell proliferation and migration (54). The results of the present study demonstrated that NRP2 was overexpressed in the G1 group when compared with the control group $[\mathrm{FC}=(+) 1.8525)]$, and was the most over-represented gene. If the information presented is reliable, it is possible that cancer cells at this stage demonstrate increased pro-angiogenic interactions between VEGF and NRP2 in G1 compared with control, which may promote increased angiogenesis and subsequent cancer progression. SEMA3F is an inhibitor of cell adhesion and migration, which is partially due to signaling alterations that affect the activation or stabilization of surface integrins $(61,62)$. Integrin inhibition by SEMA3F may explain the inhibition of endothelial and cancer cell migration, which leads to a reduction of angiogenesis and metastasis $(63,64)$.

It is considered that at least two protein members of the class 3 SEMA family, one of which includes SEMA3F, exhibit antiangiogenic effects involving NRPs (65). Microarray analysis performed in the current study, demonstrated that SEMA3B and $3 \mathrm{~F}$ of the class 3 SEMA family, were overexpressed in endometrial adenocarcinoma samples when compared with controls. SEMA3B was identified as the over-represented gene in the $\mathrm{G} 2$ vs. control groups, and SEMA3F was the over-represented gene in the G3 vs. control groups. Overexpression of SEMA3F may inhibit cellular migration, which may result in a reduction of angiogenesis (61).

It has been previously demonstrated that SEMA3F inhibits angiogenesis, cell proliferation and cell survival, which are induced by VEGF and basic fibroblast growth factor (bFGF) (66). The lack of bFGF-binding NRPs, coupled with the fact that SEMA3F does not inhibit binding of bGFG to its receptor, indicate that SEMA3F may function through NRP2 (66-68). Additional studies have demonstrated that SEMA3F inhibits tumor angiogenesis in vivo. Previous studies have suggested that, VEGF promotes angiogenesis via NRP2, while SEMA3F is an inhibitor of angiogenesis (66). These features of NRP and SEMA3Findicate that they may be potential targets for anti-angiogenic therapy. The direct effect of VEGF on endothelial cells has long been established; however, the role of the NRP in this process is currently under investigation. Angiogenic induction through the binding of VEGF to NRP2 has been characterized to a limited extent, and the evidence presented so far suggests that the regulation occurs in a different manner to that of VEGF-NRP1 (46). Favier et al (65) investigated the role of NRP2 in primary human endothelial cells, and the results indicated that NRP2 interacts with VEGFR2 and VEGFR3. By assessing the overexpression or suppression of NRP2, an essential role of NRP2 in the survival and migration of endothelial cells induced by VEGFA and VEGFC was demonstrated. In 
addition, this previous study demonstrated that NRP2 functions as a co-receptor for VEGFR. As VEGFR2 is always present on endothelial cells, whereas VEGFR3 is expressed, it was demonstrated that NRP2 interacts with VEGFR3 and VEGFR2. VEGFR2 is responsible for the full spectrum of action of VEGF factors on endothelial cells. Unlike VEGFR1, expression of the VEGFR2 gene is not dependent on hypoxia (69). Expression of VEGFR2 occurs primarily in vascular endothelial cells and in megakaryocytes, platelets and hematopoietic stem cells (70-72). The expression of VEGFR3 regulates the development and growth of the lymphatic system (73). Embryos with a defective VEGFR3 gene succumb at an early stage of development due to malformation of the cardiovascular system (74). In adults, expression of this isoform occurs exclusively in the endothelial lymphatic vessels. In addition, its expression was identified in the blood vessels of various tumors during neovascularization, which is associated with the spread of the tumor process. If the interaction between VEGFR and NRP2 is supported by a co-ligand, it is possible that NRP2 may function as a co-receptor for VEGFR2 and VEGFR3. The results obtained by Favier et al (65) demonstrated that NRP2 functions as a co-receptor for VEGFR in response to VEGFC. The present study demonstrated that VEGFC was strongly silenced in G2 and G3 endometrial adenocarcinomas. This may be due to the marked decrease in the concentration of a specific mRNA, which affects the decrease in survival and migration of endothelial cells.

SEMA5A demonstrates oncogenic and tumor suppressive functions in a number of cancers. High expression of SEMA5A and its receptor, plexin-B3, is associated with the aggressiveness of pancreatic and prostate cancers. It was demonstrated that their expression was the primary factor underlying the involvement of SEMA5A in the invasion, migration, proliferation and growth of tumors $(64,75,76)$. In vitro studies have demonstrated that one of the consequences of SEMA5A expression is a decrease in the level of apoptosis of endothelial cells $(75,77)$. Furthermore, downregulation of SEMA5A at the transcriptional and translational levels was observed in lung cancer samples, which is generally associated with low survival rates (78). The use of microarrays in the present study demonstrated that SEMA5A is silenced [FC $=(-) 3.5141]$ in G2 and G3 endometrial adenocarcinomas when compared with controls. Based on these observations, it is possible that SEMA5A may not be associated with cancer aggressiveness.

EDIL3, also termed DEL-1, was one of the first extracellular matrix proteins determined to be involved in vascular morphogenesis. EDIL3 has been investigated extensively, and is associated with the regulation of angiogenesis and cell adhesion. It is an embryonic endothelial cell protein, which is not expressed following birth; however, it is expressed in numerous tumor types $(79,80)$. The current study demonstrated that EDIL3 was overexpressed in the G1 vs. control groups $(\mathrm{FC}=(+) 1.7940)$. Overexpression of EDIL3 reduces apoptosis of tumor cells and leads to increased tumor vascularization, which promotes tumor growth $(80,81)$. The potential modulation of tumor vasculature by EDIL3 may be a potential target for anti-angiogenic therapy of cancer $(82,83)$.

In conclusion, the results of the present study provide potential novel results that may facilitate diagnosis and treatment of patients with endometrial cancer. The scientific value of the present study has been discussed; however, certain limitations have to be considered. The small total number of collected and selected samples analyzed, may affect the impact of the current study. In order to improve the results further, a study that includes a higher number of patients would be desirable. The results of the present study indicate that NRP2 may demonstrate an important role in the activity of endothelial cells, including VEGF, and potentially plexins and integrins. An understanding of how these proteins interact remains to be established. In the future, this may lead to an improved understanding of the mechanisms underlying angiogenesis. The results of the present study indicate that NRP2 may be a worthwhile target for future pharmacological studies.

\section{References}

1. Ong FS, Das K, Wang J, Vakil H, Kuo JZ, Blackwell WL, Lim SW, Goodarzi MO, Bernstein KE, Rotter JI and Grody WW: Personalized medicine and pharmacogenetic biomarkers: Progress in molecular oncology testing. Expert Rev Mol Diagn 12: 593-602, 2012.

2. Biankin VA, Piantadosi S and Hollingsworth SJ: Patient-centric trials for therapeutic development in precision oncology. Nature 526: 361-370, 2015.

3. Le Tourneau C, Kamal M, Tsimberidou AM, Bedard P, Pierron G, Callens C, Rouleau E, Vincent-Salomon A, Servant N, Alt M, et al: Treatment algorithms based on tumor molecular profiling: The essence of precision medicine trials. J Natl Cancer Inst 108: djv362, 2015.

4. Yamaguchi T, Bando H, Mori T, Takahashi K, Matsumoto H, Yasutome M, Weich $\mathrm{H}$ and Toi M: Over expression of soluble vascular endothelial growth factor receptor 1 in colorectal cancer: Association with progression and prognosis. Cancer Sci 98: 405-410, 2007.

5. Lesslie DP, Summy JM, Parikh NU, Fan F, Trevino JG, Sawyer TK, Metcalf CA, Shakespeare WC, Hicklin DJ, Ellis LM and Gallick GE: Vascular endothelial growth factor receptor-1 mediates migration of human colorectal carcinoma cells by activation of Src family kinases. Br J Cancer 94: 1710-1717, 2006

6. Ziyad S and Iruela-Arispe ML: Molecular mechanisms of tumor angiogenesis. Genes Cancer 2: 1085-1096, 2011.

7. Lanara Z, Giannopoulou E, Fullen M, Kostantinopoulos E, Nebel JC, Kalofonos HP, Patrinos GP and Pavlidis C: Comparative study and meta-analysis of meta-analysis studies for the correlation of genomic markers with early cancer detection. Hum Genomics 7: 14, 2013.

8. Caunt M, Mak J, Liang WC, Stawicki S, Pan Q, Tong RK, Kowalski J, Ho C, Reslan HB, Ross J, et al: Blocking neuropilin-2 function inhibits tumor cell metastasis. Cancer Cell 13: 331-342, 2008.

9. Pan Q, Chanthery Y, Liang WC, Stawicki S, Mak J, Rathore N, Tong RK, Kowalski J, Yee SF, Pacheco G, et al: Blocking neuropilin-1 function has an additive effect with anti-VEGF to inhibit tumor growth. Cancer Cell 11: 53-67, 2007.

10. Rajaganeshan R, Prasad R, Guillou PJ, Chalmers CR, Scott N, Sarkar R, Poston G and Jayne DG: The influence of invasive growth pattern and microvessel density on prognosis in colorectal cancer and colorectal liver metastases. Br J Cancer 96: 1112-1127, 2007.

11. Gee MG, Procopio WN, Makonnen S, Feldman MD, Yeilding NM and Lee WM: Tumor vessel development and maturation impose limits on the effectiveness of anti-vascular therapy. Am J Pathol 162: 183-193, 2003.

12. Xian X, Håkansson J, Ståhlberg A, Lindblom P, Betsholtz C, Gerhardt $\mathrm{H}$ and Semb H: Pericytes limit tumor cell metastasis. J Clin Invest 116: 642-651, 2006.

13. Romani AA, Borghetti AF, Del Rio P, Sianesi M and Soliani P: The risk of developing metastatic disease in colorectal cancer is related to CD105-positive vessel count. J Surg Oncol 93: 446-455, 2006. 
14. Saad RS, Liu YL, Nathan G, Celebrezze J, Medich D and Silverman JF: Endoglin (CD105) and vascular endothelial growth factor as prognostic markers in colorectal cancer. Mod Pathol 17: 197-203, 2004

15. Kölbl AC, Birk AE, Kuhn C, Jeschke U and Andergassen U: Influence of VEGFR and LHCGR on endometrial adenocarcinoma. Oncol Lett 12: 2092-2098, 2016.

16. Trimble CL, Method M, Leitao M, Lu K, Ioffe O, Hampton M, Higgins R, Zaino R and Mutter GL; Society of Gynecologic Oncology Clinical Practice Committee: Management of endometrial precancers. Obstet Gynecol 120: 1160-1175, 2012.

17. Klemba A, Kukwa W, Bartnik W, Krawczyk T, Scińska A, Golik P and Czarnecka AM: Molecular biology of endometrial carcinoma. Postepy Hig Med Dosw (online) 62: 420-432, 2008 (In Polish).

18. Colombo N, Preti E, Landoni F, Carinelli S, Colombo A, Marini C and Sessa C; ESMO Guidelines Working Group: Endometrial cancer: ESMO clinical practice guidelines for diagnosis, treatment and follow-up. Ann Oncol 22 (Suppl 6): vi35-vi39, 2011.

19. Murali R, Soslow RA and Weigelt B: Classification of endometrial carcinoma: More than two types. Lancet Oncol 15: e268-e278, 2014.

20. Witek $Ł$, Janikowski T, Bodzek P, Olejek A and Mazurek U: Expression of tumor suppressor genes related to the cell cycle in endometrial cancer patients. Adv Med Sci 61: 317-324, 2016.

21. Mi H, Huang X, Muruganujan A, Tang H, Mills C, Kang D and Thomas PD: PANTHER version 11: Expanded annotation data from gene ontology and reactome pathways and data analysis tool enhancements. Nucleic Acids Res 45: D185-D189, 2017.

22. Bolstad BM, Irizarry RA, Astrand M and Speed TP: A comparison of normalization methods for high density oligonucleotide array data based on bias and variance. Bioinformatics 19: 185-193, 2003.

23. Chrominski K and Tkacz M: Comparison of high-level microarray analysis methods in the context of result consistency. PLoS One 10: e0128845, 2015.

24. Kim WH, Lee SH, Jung MH, Seo JH, Kim J, Kim MA and Lee YM: Neuropilin2 expressed in gastric cancer endothelial cells increases the proliferation and migration of endothelia cells in response to VEGF. Exp Cell Res 315: 2154-2164, 2009.

25. Gluzman-Poltorak Z, Cohen T, Shibuya M and Neufeld G Vascular endothelial growth factor receptor-1 and neuropilin-2 form complexes. J Biol Chem 276: 18688-18694, 2001.

26. Nassiri F, Cusimano MD, Scheithauer BW, Rotondo F, Fazio A Yousef GM, Syro LV, Kovacs K and Lloyd RV: Endoglin (CD105): A review of its role in angiogenesis and tumor diagnosis, progression and therapy. Anticancer Res 31: 2283-2290, 2011.

27. Bernabeu C, Lopez-Novoa JM and Quintanilla M: The emerging role of TGF-beta superfamily coreceptors in cancer. Biochim Biophys Acta 1792: 954-973, 2009.

28. Wong SH, Hamel L, Chevalier S and Philip A: Endoglin expression on human microvascular endothelial cells association with betaglycan and formation of higher order complexes with TGF-beta signaling receptors. Eur J Biochem 267: 5550-5560, 2000.

29. Blobe GC, Schiemann WP and Lodish HF: Role of transforming growth factor $\beta$ in human disease. N Engl J Med 342: 1350-1358, 2000 .

30. Govinden R and Bhoola KD: Genealogy, expression, and cellular function of transforming growth factor-beta. Pharmacol Ther 98 257-265, 2003.

31. Zhu HJ and Burgess AW: Regulation of transforming growth factor-beta signaling. Mol Cell Biol Res Commun 4: 321-330, 2001.

32. Hata A, Shi Y and Massagué J: TGF-beta signaling and cancer: Structural and functional consequences of mutations in Smads. Mol Med Today 4: 257-262, 1998.

33. Li C, Hampson IN, Hampson L, Kumar P, Bernabeu C and Kumar S: CD105 antagonizes the inhibitory signaling of transforming growth factor beta1 on human vascular endothelial cells. FASEB J 14: 55-64, 2000.

34. Jerkic M, Rivas-Elena JV, Prieto M, Carrón R, Sanz-Rodríguez F, Pérez-Barriocanal F, Rodríguez-Barbero A, Bernabéu C and López-Novoa JM: Endoglin regulates nitric oxide-dependent vasodilatation. FASEB J 18: 609-611, 2004

35. Jerkic M, Rodríguez-Barbero A, Prieto M, Toporsian M, Pericacho M, Rivas-Elena JV, Obreo J, Wang A, Pérez Barriocanal F, Arévalo M, et al: Reduced angiogenic responses in adult Endoglin heterozygous mice. Cardiovasc Res 69: 845-854, 2006
36. Alev C, McIntyre BA, Ota K and Sheng G: Dynamic expression of Endoglin, a TGF-beta co-receptor, during pre-circulation vascular development in chick. Int J Dev Biol 54: 737-742, 2010.

37. Folkman J, Watson K, Ingber D and Hanahan D: Induction of angiogenesis during the transition from hyperplasia to neoplasia. Nature 339: 58-61, 1989.

38. Cheifetz S, Bellón T, Calés C, Vera S, Bernabeu C, Massagué J and Letarte M: Endoglin is a component of the transforming growth factor-beta receptor system in human endothelial cells. J Biol Chem 267: 19027-19030, 1992.

39. Barbara NP, Wrana JL and Letarte M: Endoglin is an accessory protein that interacts with the signaling receptor complex of multiple members of the transforming growth factor-beta superfamily. J Biol Chem 274: 584-594, 1999.

40. Li DY, Sorensen LK, Brooke BS, Urness LD, Davis EC, Taylor DG, Boak BB and Wendel DP: Defective angiogenesis in mice lacking endoglin. Science 284: 1534-1537, 1999.

41. Burrows FJ, Derbyshire EJ, Tazzari PL, Amlot P, Gazdar AF, King SW, Letarte M, Vitetta ES and Thorpe PE: Up-regulation of endoglin on vascular endothelial cells in human solid tumors: Implications for diagnosis and therapy. Clin Cancer Res 1: 1623-1634, 1995.

42. Wang JM, Kumar S, Pye D, Haboubi N and al-Nakib L: Breast carcinoma: Comparative study of tumor vasculature using two endothelial cell markers. J Natl Cancer Inst 86: 386-388, 1994.

43. Duff SE, Li C, Garland JM and Kumar S: CD105 is important for angiogenesis: Evidence and potential applications. FASEB J 17: 984-992, 2003

44. Pérez-Gómez E, Del Castillo G, Juan Francisco S López-Novoa JM, Bernabéu C and Quintanilla M: The role of the TGF- $\beta$ coreceptor endoglin in cancer. ScientificWorldJournal 10: 2367-2384, 2010

45. Craft C, Romero D, Vary C and Bergan R: Endoglin inhibits prostate cancer motility via activation of the ALK2-Smad1 pathway. Oncogene 26: 7240-7250, 2007.

46. Oh H, Takagi H, Otani A, Koyama S, Kemmochi S, Uemura A and Honda Y: Selective induction of neuropilin-1 by vascular endothelial growth factor (VEGF): A mechanism contributing to VEGF-induced angiogenesis. Proc Natl Acad Sci USA 99: 383-388, 2002.

47. Stephenson JM, Banerjee S, Saxena NK, Cherian R and Banerjee SK: Neuropilin-1 is differentially expressed in myoepithelial cells and vascular smooth muscle cells in preneoplastic and neoplastic human breast: A possible marker for the progression of breast cancer. Int J Cancer 101: 409-414, 2002.

48. Yang H, Li M, Chai H, Yan S, Lin P, Lumsden AB, Yao Q and Chen C: Effects of cyclophilin A on cell proliferation and gene expressions in human vascular smooth muscle cells and endothelial cells. J Surg Res 123: 312-319, 2005.

49. Broholm $\mathrm{H}$ and Laursen $\mathrm{H}$ : Vascular endothelial growth factor (VEGF) receptor neuropilin-1's distribution in astrocytic tumors. APMIS 112: 257-263, 2004

50. Fakhari M, Pullirsch D, Abraham D, Paya K, Hofbauer R, Holzfeind P, Hofmann M and Aharinejad S: Selective upregulation of vascular endothelial growth factor receptors neuropilin-1 and -2 in human neuroblastoma. Cancer 94: 258-263, 2002.

51. Straume $O$ and Akslen LA: Increased expression of VEGF-receptors (FLT1, KDR, NRP-1) and thrombospondin-1 is associated with glomeruloid microvascular proliferation, an aggressive angiogenic phenotype, in malignant melanoma. Angiogenesis 6: 295-301,2003.

52. Miao HQ and Klagsbrun M: Neuropilin is a mediator of angiogenesis. Cancer Metastasis Rev 19: 29-37, 2000.

53. Appleton BA, Wu P, Maloney J, Yin J, Liang WC, Stawicki S Mortara K, Bowman KK, Elliott JM, Desmarais W, et al: Structural studies of neuropilin/antibody complexes provide insights into semaphorin and VEGF binding. EMBO J 26 : 4902-4912, 2007

54. Yazdani U and Terman JR: The semaphorins. Genome Biol 7 211,2006

55. Janssen BJ, Malinauskas T, Weir GA, Cader MZ, Siebold C and Jones EY: Neuropilins lock secreted semaphorins onto plexins in a ternary signaling complex. Nat Struct Mol Biol 19: 1293-1299, 2012.

56. Lepelletier Y, Moura IC, Hadj-Slimane R, Renand A, Fiorentino S, Baude C, Shirvan A, Barzilai A and Hermine O: Immunosuppressive role of semaphorin-3A on T cell proliferation is mediated by inhibition of actin cytoskeleton reorganization. Eur J Immunol 36: 1782-1793, 2006 
57. Delgoffe GM, Woo SR, Turnis ME, Gravano DM, Guy C, Overacre AE, Bettini ML, Vogel P, Finkelstein D, Bonnevier J, et al: Stability and function of regulatory T cells is maintained by a neuropilin-1-semaphorin-4a axis. Nature 501: 252-256, 2013

58. Uniewicz KA and Fernig DG: Neuropilins: A versatile partner of extracellular molecules that regulate development and disease. Front Biosci 13: 4339-4360, 2008.

59. Roth L, Nasarre C, Dirrig-Grosch S, Aunis D, Crémel G Hubert P and Bagnard D: Transmembrane domain interactions control biological functions of neuropilin-1. Mol Biol Cell 19: 646-654, 2008.

60. Raimondi C and Ruhrberg C: Neuropilin signalling in vessels, neurons and tumours. Semin Cell Dev Biol 24: 172-178, 2013.

61. Potiron VA, Roche J and Drabkin HA: Semaphorins and their receptors in lung cancer. Cancer Lett 273: 1-14, 2009.

62. Potiron V and Roche J: Class 3 semaphorin signaling: The end of a dogma. Sci STKE 285: pe24, 2005.

63. Kruger RP, Aurandt J and Guan KL: Semaphorins command cells to move. Nat Rev Mol Cell Biol 6: 789-800, 2005.

64. Serini G, Napione L, Arese M and Bussolino F: Besides the adhesion: New perspectives of integrin functions in angiogenesis. Cardiovasc Res 78: 213-222, 2008

65. Favier B, Alam A, Barron P, Bonnin J, Laboudie P, Fons P, Mandron M, Herault JP, Neufeld G, Savi P, et al: Neuropilin-2 interacts with VEGFR-2 and VEGFR-3 and promotes human endothelial cell survival and migration. Blood 108: 1243-1250, 2006.

66. Kessler O, Shraga-Heled N, Lange T, Gutmann-Raviv N, Sabo E, Baruch L, Machluf M and Neufeld G: Semaphorin-3F is an inhibitor of tumor angiogenesis. Cancer Res 64: 1008-1015, 2004

67. Chen H, Chédotal A, He Z, Goodman CS and Tessier-Lavigne M: Neuropilin-2, a novel member of the neuropilin family, is a high affinity receptor for the semaphorins Sema E and Sema IV but not Sema III. Neuron 19: 547-559, 1997.

68. Giger RJ, Urquhart ER, Gillespie SK, Levengood DV, Ginty DD and Kolodkin AL: Neuropilin-2 is a receptor for semaphorin IV: Insight into the structural basis of receptor function and specificity. Neuron 21: 1079-1092, 1998.

69. Karkkainen MJ and Petrova TV: Vascular endothelial growth factor receptors in the regulation of angiogenesis and lymphangiogenesis. Oncogene 19: 5598-5605, 2000.

70. Rahimi N: Vascular endothelial growth factor receptors: Molecular mechanisms of activation and therapeutic potentials. Exp Eye Res 83: 1005-1016, 2006.

71. Kowanetz M and Ferrara N: Vascular endothelial growth factor signaling pathways: Therapeutic perspective. Clin Cancer Res 12: 5018-5022, 2006.

72. Cebe-Suarez S, Zehnder-Fjallman A and Ballmer-Hofer K: The role of VEGF receptors in angiogenesis; complex partnerships. Cell Mol Life Sci 63: 601-15, 2006.
73. Iljin K, Karkkainen MJ, Lawrence EC, Kimak MA, Uutela M, Katri JT, Alhonen PL, Halmekytö M, Finegold DN, Ferrell RE and Alitalo K: VEGFR3 gene structure, regulatory region, and sequence polymorphisms. FASEB J 15: 1028-1036, 2001.

74. Saharinen P, Tammela T, Karkkainen MJ and Alitalo K: Lymphatic vasculature: Development, molecular regulation and role in tumor metastasis and inflammation. Trends Immunol 25: 387-95, 2004

75. Sadanandam A, Varney ML, Singh S, Ashour AE, Moniaux N, Deb S, Lele SM, Batra SK and Singh RK: High gene expression of semaphorin $5 \mathrm{~A}$ in pancreatic cancer is associated with tumor growth, invasion and metastasis. Int J Cancer 127: 1373-1383, 2010.

76. Pan G, Lv H, Ren H, Wang Y, Liu Y, Jiang H and Wen J: Elevated expression of semaphorin $5 \mathrm{~A}$ in human gastric cancer and its implication in carcinogenesis. Life Sci 86: 139-144, 2010.

77. Pan GQ, Ren HZ, Zhang SF, Wang X and Wen J: Expression of semaphorin $5 \mathrm{~A}$ and its receptor plexin $\mathrm{B} 3$ contributes to invasion and metastasis of gastric carcinoma. World J Gastroenterol 15: 2800-2804, 2009.

78. Resende C, Ristimaki A and Machado JC: Genetic and epigenetic alteration in gastric carcinogenesis. Helicobacter 15 (Suppl 1): S34-S39, 2010.

79. Jiang SH, Wang Y, Yang JY, Li J, Feng MX, Wang YH, Yang XM, He P, Tian GA, Zhang XX, et al: Overexpressed EDIL3 predicts poor prognosis and promotes anchorage-independent tumor growth in human pancreatic cancer. Oncotarget 7: 4226-4240, 2016.

80. Aoka Y, Johnson FL, Penta K, Hirata Ki K, Hidai C, Schatzman R, Varner JA and Quertermous T: The embryonic angiogenic factor Del1 accelerates tumor growth by enhancing vascular formation. Microvasc Res 64: 148-161, 2002.

81. Sadanandam A, Rosenbaugh EG, Singh S, Varney M and Singh RK: Semaphorin 5A promotes angiogenesis by increasing endothelial cell proliferation, migration, and decreasing apoptosis. Microvasc Res 79: 1-9, 2010.

82. Lu TP, Tsai MH, Lee JM, Hsu CP, Chen PC, Lin CW, Shih JY, Yang PC, Hsiao CK, Lai LC and Chuang EY: Identification of a novel biomarker, SEMA5A, for non-small cell lung carcinoma in nonsmoking women. Cancer Epidemiol Biomarkers Prev 19: 2590-2597, 2010.

83. Ferrara N and Kerbel RS: Angiogenesis as a therapeutic target. Nature 438: 967-974, 2005. 